'confused' patients falling between psychiatric and geriatric services; assessors tend to underestimate ill health; criteria for urgent admission should be acute failure of community to cope rather than our own 'abstract criteria'; and two specific complaints about cases. In one, the GP felt that we had left too much responsibility with the family in finding a private nursing home. In the other, the GP criticised our refusals to treat under compulsory order a demented patient who was putting her life at risk by refusing surgery.

\section{Comments}

This survey was designed to have direct relevance to the local service. A number of areas were revealed which merited review by our unit: the need for same day assessment, the usefulness of prompt communications, greater explicitness over boundaries and sharing of responsibility, and suspicion of the role of non-medical involvement in assessment. In this way, a survey of GPs proved a useful and cost-effective way of evaluating a new unit. The results needed careful interpretation. Global approval ratings might more accurately reflect politeness or personal relationships than real changes in the quality of service. Specific complaints may reflect genuine shortcomings or idiosyncratic expectations. In this study, a number of GPs appeared to regard the previous system with nostalgia, presumably because patients were more readily admitted, less often discharged, and therefore caused fewer problems. In interpreting the results, the consistency of each judgement must be borne in mind both in terms of the survey itself and in comparison with other formal and informal mechanisms of feedback.
The results have wider significance. Other districts with similar objectives may find the specific areas of difficulty of relevance. Moreover, the survey method may be useful to other groups. More broadly, some judgements about Arie \& Jolley's ${ }^{2}$ principles can be made. Most appear to be acceptable to GPs, although responsiveness and full, clear collaboration may be hard to achieve. One principle which may need more thought is the un-hiearchical use of staff in a multidisciplinary team. It is unclear whether suspicion of non-medical disciplines results from unfamiliarity or reflects real disadvantages from the GP's viewpoint. If the former, then it is a public relations problem but if the latter, many services will need to re-evaluate their systems.

\section{References}

${ }^{1}$ Government Response to the Second Report from the Social Services Committee, 1984-85 session: Community Care with Special Reference to the Adult Mentally Ill and Mentally Handicapped People (1985) (Cmnd. 9674). London: HMSO.

${ }^{2}$ ARIE, \& JOLLEY, D. (1982) Making services work: organisation and style of psychogeriatric services In The Psychiatry of Late Life, (eds, R. Levy \& F. Post) Oxford: Blackwell.

${ }^{3}$ HORROCKS, P. (1986) The components of a comprehensive district health service for elderly people - a personal view. Age and Ageing, 15, 321-342.

${ }^{4}$ National Health Service Health Advisory Service (1983) The Rising Tide. London: Department of Health \& Social Security.

${ }^{5}$ Wattis, J., WATtIS, L. \& ARIE, T. (1981) Psychogeriatrics: a national survey of a new branch of psychiatry. British Medical Journal, 282, 1529-1533.

\title{
Psychiatrists' use of investigations
}

\author{
Anthony White, Senior Registrar in Psychiatry, Glenside Hospital, Stapleton, Bristol
}

Many westernised countries have introduced Quality Assurance (QA) into their process of health care. The UK has lagged behind other countries and psychiatry has lagged behind other specialities.

In 1980 the Australian Department of Health formed a seven member QA project team run by the Royal Australian and New Zealand College of Psychiatrists in an attempt to establish a methodology for QA in psychiatry. Using three sources of information: literature review, survey of views of practising psychiatrists and the views of an expert committee, they have now reported on the main categories of psychiatric illness. Their more recent reports have enjoyed publication in this country, suggesting the findings are of interest and relevance to us. ${ }^{1}$

Absent from the Australia and New Zealand QA surveys is any appraisal of physical illness in the 
patients presenting with the psychiatric conditions they are purporting to manage. This is reasonable if the intention is to advise upon the management of purely functional illness. However, a diagnosis of functional illness requires exclusion of organic disease. This may require physical investigation. Since the inception of QA, physical investigations have proved a suitable testing ground for one of the central procedures of QA, clinical audit. ${ }^{2}$

Laboratory and radiological investigations cost the DHSS several hundred million pounds annually. Understandably there has been an enormous effort to devise effective methods to audit the use of these investigations and demonstrate inconsistencies of practice. For example, in general medicine the number of tests used to investigate a particular disease has been shown to vary 20 -fold between hospitals. ${ }^{3}$ The argument is that, provided outcome measures are similar, there is no reason why the lower figure should not be adopted more widely.

By comparison with the technological progress in physical medicine, the interface between mental and physical illness remains an unknown area. There is no consistent agreement about the amount of investigation that is warranted in the mentally ill. Studies can be cited where the proportion of psychiatric patients in whom physical illness is judged to have a causal role is as low as zero or as high as $50 \%$.4.5 According to which figure is adopted, the recommended level of investigation, and therefore expenditure, can vary many-fold.

To draw together these unknown aspects of the relationship between physical and mental illness and the differing views about management, I employed one of the methods used by the Australia and New Zealand QA project team: a survey of practising psychiatrists' views. I sought to establish the range of opinion about practical use of investigations and document the effect of some obvious influences on usè.

\section{The study}

During 1987 I circulated all adult psychiatrists in Avon with a questionnaire about how they would manage six cases which were described in accompanying clinical vignettes. Respondents were asked to indicate which of a list of 35 common investigations they would consider important to perform in making their assessment of each case on or soon after admission. The case vignettes were all similar except for the presence or absence of an abnormal clinical finding. In each of four of the cases a positive finding was described in one of the four main areas: past psychiatric history, past medical history, family psychiatric history and physical examination. The remaining two cases had no positive findings other than mental illness.
The respondents were only examined for one variable, the grade of their post held.

Of 72 psychiatrists in the study, 57 completed the questionnaire, two politely declined and 15 did not reply despite two reminders, making a response rate of $82 \%$.

\section{The findings}

In examining the responses, the first important point is the minimal alteration of investigating behaviour according to clinical findings.

Of the six case histories supplied with the questionnaire, a 'typical case' with no clinical evidence of physical disease or past or family psychiatric disease can be taken as a baseline. The questionnaire contained two such cases. Compared with these baseline cases, the presence of a clinical finding of any type did not significantly alter the mean number of investigations that the psychiatrists would use (Table I). Only a trend in the expected direction was seen, a physical finding increasing the use of investigation and a past or family psychiatric history decreasing the use of investigation. Only comparison between the extreme examples of a case with positive physical findings compared with a known history of psychiatric disease gives a statistically significant difference in investigation.

The second point the responses demonstrate is the different investigating behaviour between psychiatrists according to their grade. Table II shows that doctors tend to use many investigations early in their psychiatric career, increasing from senior house officer to a peak at registrar level and decreasing to a minimum as consultant. The difference is statistically significant between most grades, even between adjacent rungs of the career ladder.

A third point arises from a comparison of these first two points. The extent of investigation was barely influenced by clinical findings, yet investigation was greatly influenced by the post held by the psychiatrist, reaching a three-fold difference between registrars and consultants. In crude terms, investigation depends more upon the doctor than upon the patient.

This last finding becomes more understandable when the views of the four psychogeriatricians are examined. Their views were also canvassed, though they were not included in the survey of adult psychiatrists. Use of investigations by each psychogeriatrician exceeded that of any adult psychiatrist. Presumably the psychogeriatricians extrapolated their habitual organic approach, appropriate in the elderly, to the adult age group cited in the case vignettes.

The same extrapolation may explain the high use of investigations by doctors who are new in psychiatry. Fresh from the theoretical proving grounds 
TABLE I

Intercorrelations between cases in the number of investigations performed

\begin{tabular}{|c|c|c|c|c|c|c|}
\hline \multirow[b]{2}{*}{ Case history } & \multirow{2}{*}{$\begin{array}{l}\text { Mean number } \\
\quad \text { of } \\
\text { investigations }\end{array}$} & \multicolumn{5}{|c|}{ Case history } \\
\hline & & 2 & 3 & 4 & 5 & 6 \\
\hline $\begin{array}{l}\text { Cases with evidence of predisposition to ment } \\
\text { 1. Positive past psychiatric history } \\
\text { 2. Positive family psychiatric history }\end{array}$ & $\begin{array}{l}10.93 \\
10.70\end{array}$ & NS & $\begin{array}{l}\text { NS } \\
\text { NS }\end{array}$ & $\begin{array}{l}\text { NS } \\
\text { NS }\end{array}$ & $\begin{array}{l}\text { NS } \\
\text { NS }\end{array}$ & $\begin{array}{l}P<0.01 \\
P<0.01\end{array}$ \\
\hline $\begin{array}{l}\text { Baseline cases } \\
\text { 3. No clinical findings } \\
\text { 4. No clinical findings }\end{array}$ & $\begin{array}{l}12.63 \\
11.20\end{array}$ & & & NS & $\begin{array}{l}\text { NS } \\
\text { NS }\end{array}$ & $\begin{array}{l}\text { NS } \\
\text { NS }\end{array}$ \\
\hline $\begin{array}{l}\text { Cases with clinical evidence of physical illness } \\
\text { 5. Positive past medical history } \\
\text { 6. Positive finding on physical examination }\end{array}$ & $\begin{array}{l}12.07 \\
15.06\end{array}$ & & & & & NS \\
\hline
\end{tabular}

Student's $t$-test.

TABLE II

Intercorrelations between grades in the number of investigations performed

\begin{tabular}{|c|c|c|c|c|c|}
\hline $\begin{array}{l}\text { Rank } \\
\text { Total number in grade } \\
\text { Mean no. of investigations } \\
\text { (Standard deviation) }\end{array}$ & $\begin{array}{c}\text { Senior House } \\
\text { Officer } \\
11 \\
76.1 \\
(21.1)\end{array}$ & $\begin{array}{c}\text { Registrar } \\
11 \\
100.2 \\
(37.5)\end{array}$ & $\begin{array}{c}\text { Clinical } \\
\text { Assistant } \\
12 \\
97.3 \\
(33.4)\end{array}$ & $\begin{array}{c}\text { Senior } \\
\text { Registrar } \\
7 \\
57.3 \\
(40.7)\end{array}$ & $\begin{array}{c}\text { Consultant } \\
13 \\
32.1 \\
(20.8)\end{array}$ \\
\hline $\begin{array}{l}\text { Consultant } \\
\text { Senior Registrar } \\
\text { Clinical Assistant } \\
\text { Registrar }\end{array}$ & $\begin{array}{c}P<0.001 \\
\text { NS } \\
\text { NS } \\
0.02<P<0.05\end{array}$ & $\begin{aligned} P & <0.001 \\
0.02 & <P<0.05 \\
\text { NS } & -\end{aligned}$ & $\begin{array}{c}P<0.001 \\
\text { NS } \\
- \\
-\end{array}$ & $\begin{aligned} 0.02< & P \\
- & <0.005 \\
- & -\end{aligned}$ & $\begin{array}{l}- \\
- \\
-\end{array}$ \\
\hline
\end{tabular}

Student's $t$-test.

of medical school and postgraduate study, these juniors presumably enter psychiatry full of enthusiasm to diagnose the case of Wilson's disease or parasagittal meningioma that the textbooks and lectures would have us believe languishes in every back ward.

\section{Comment}

The fundamental principles underlying this tendency to perseverate practice from one situation to another are stated by Tversky \& Kahneman in their paper on judgement under uncertainty. ${ }^{6}$ Tracing from origins in cognitive psychology, they describe three cognitive principles which they term heuristics: the representative heuristic, availability heuristic and anchoring and adjustment heuristic. Tversky \& Kahneman demonstrate how these principles account for bias in our thinking in a wide range of different circum- stances, ranging from judging distances in fog to guessing a stranger's occupation, or gambling.

Credit goes to Sox for applying these cognitive principles to the way physicians use diagnostic tests. ${ }^{7}$ Particularly pertinent are the availability and anchoring and adjustment heuristics. The availability heuristic describes how the probability of an event is judged by the ease with which similar events are recalled. In medicine, a diagnosis is judged to be probable because of the ease with which similar diagnoses are recalled. When put like this, it is easy to see the effect of the emphasis given to the rare, the unlikely, even the unique case in clinical teaching and experience.

The anchoring and adjustment heuristic describes the process of changing one's estimate of the likelihood of an event in the light of new information. Many experimental models of this principle exist. ${ }^{6}$ 
The pertinent example here consists of the way clinicians are reluctant to discard an idea about diagnosis despite refutatory evidence. They continue to use more extravagant tests in a striving to make their predictions come true.

The crucial common element in these processes is the tendency to register unusual events more prominently than usual or predicted events.

Why is this a problem? I see two reasons. Firstly there is the conceptual problem that the results of investigations all too readily provide something to clutch at when faced with the frustrations of a functional illness. I remain uncertain whether this is best explained cognitively, as misconstrued cognitions, or psychodynamically, as a manifestation of a latent primitive need to have our difficulties explained and remedied by a higher intellectual power. The conventional psychodynamic factors which contribute to functional symptoms in patients have been well described over the last century. I believe we need to acknowledge that some of the influences of biomedical technology are probably also incorporated into the subconscious forces in which we are all susceptible. Sox et $a l^{8}$ have demonstrated the psychological value of investigations for patients, though without providing a theoretical explanation. I suspect doctors find a comparable value in investigations, but demonstrating this is more difficult.

The second reason why this inappropriate use of tests is a problem is economic. The present climate of clinical budgeting and accountability necessitates that areas of excess are identified and corrective measures taken. This is termed a quality cycle, the result of practical application of audit as one of the processes of QA. ${ }^{2}$

In summary, I have demonstrated just one part of a quality cycle which is relevant to psychiatry. If this particular cycle needs to be completed some possible options are very clear. One alternative is for consultants to play a greater rôle in what junior doctors do to patients. Another possibility addresses the problems posed by the wealth of information and choices of action that are available to clinicians today. Understanding of the theories of probability and decision analysis which lie behind use of this information is remarkably deficient. Better teaching in this area may encourage judgements that are free of heuristics and bias. Relevant literature is becoming available, though chiefly in the more economically orientated climate of North American medicine. ${ }^{7.9}$ For the moment I only wish to go as far as using the example of physical investigation in psychiatry in much the same way as it has been used in medicine, to show how a simple audit procedure can reveal inconsistencies of practice and open up potential cycles of change.

\section{Acknowledgements}

I am grateful to Dr Erica Jones for her advice and help over the survey. I would also like to thank all the psychiatrists in Avon who so helpfully completed the questionnaire, many also providing a wealth of unsolicited but insightful comments which have contributed to this article.

\section{References}

'ANDrews, S., Vaughan, K., Harvey, R. \& Andrews, G. (1986) A survey of practising psychiatrists' views on the treatment of schizophrenia. British Journal of Psychiatry, 149, 357-364.

${ }^{2}$ FowkEs, F. G. R. (1983) ASME Medical Education Booklet 15. Medical Audit Cycle. Medical Education, 16, 228-235.

${ }^{3}$ Ashley, J. S. A., Pasker, P. \& Beresford, J. C. (1972) How much clinical investigation? Lancet, 1, 890-892.

${ }^{4}$ WILLETT, A. B. \& KING, T. (1977) Implementation of laboratory screening procedures on a short term psychiatric inpatient unit. Diseases of the Nervous System, 38, 967-970.

${ }^{5}$ Hall, R. C. W., Gardner, E. R., Popkin, M. K., Lecann, A. F. \& STiCKNEY, S. F. (1981) Unrecognised physical illness prompting psychiatric admission: a prospective study. American Journal of Psychiatry, 138, 629-635.

${ }^{6}$ TVERSKY, A. \& KAHNEMAN, D. (1974) Judgement under uncertainty: heuristics and biases. Science, 185, 1124 1131.

${ }^{7}$ Sox, H. C. (1986) Probability theory in the use of diagnostic tests. Annals of Internal Medicine, 104, 60-66.

8 _ Margules, I. \& Sox, C. H. (1981) Psychologically mediated effects of diagnostic tests. Annals of Internal Medicine, 95, 680-685.

${ }^{9}$ Kassirer, J. P., Moskowitz, A. J., \& PAUKer, S. G. (1987) Decision analysis: a progress report. Annals of Internal Medicine, 106, 275-291. 